Atıf İçin: Torğut G, Gürler N, 2021. Grafen Katkılı Nişasta Filmlerinin Dielektrik Özelliklerinin Geniş Frekans Aralığında İncelenmesi. Iğdır Üniversitesi Fen Bilimleri Enstitüsü Dergisi, 11(2): 1393-1401.

To Cite: Torğut G, Gürler N, 2021. Investigation of Dielectric Properties of Graphene Filled Starch Films in Wide Frequency Range. Journal of the Institute of Science and Technology, 11(2): 1393-1401.

\title{
Grafen Katkılı Nişasta Filmlerinin Dielektrik Özelliklerinin Geniş Frekans Aralığında İncelenmesi
}

\section{Gülben TORĞUT ${ }^{1}$, Nedim GÜRLER $^{2 *}$}

ÖZET: Bu çalışmada, gliserol ile plastikleştirilmiş patates nişastası (PN) filmlerine, farklı oranlarda (\% 0.5, 1 , 2) grafen (G) eklenerek döküm yöntemi ile hazırlanmış filmlerin dielektrik sabiti, dielektrik kayıp ve kayıp tanjantı gibi bazı dielektrik özelliklerinin frekansla değişimleri incelendi. PN'nın saf hali ve G ile hazırlanmış kompozitlerinin (PNG0.5, PNG1 ve PNG2) dielektrik sabiti ( $)$ ), dielektrik kayıp faktörü ( $\left.\varepsilon^{\prime \prime}\right)$ ve kayıp tanjant1 $(\tan \delta)$ değerleri oda sıcaklığında frekansın bir fonksiyonu olarak (100 Hz ile $10 \mathrm{kHz}$ arasında) empedans analizör cihazı ile belirlendi. Nişastanın $1 \mathrm{kHz}$ sabit frekans ve oda sıcaklığındaki dielektrik sabiti, dielektrik kayıp ve kayıp tanjantı değerleri sırasıyla 9.20, 4.45 ve 0.48 olarak bulundu. Ayrıca, farklı oranlarda $G$ miktarının (ağırlıkça \%0.5, \%1 ve \%2) filmlerin dielektrik özellikleri üzerindeki etkisi araştırıldı. G konsantrasyonu arttıkça dielektrik sabiti, dielektrik kayıp ve kayıp tanjantı değerlerinde, saf nişastaya göre önemli artış olduğu gözlendi.

Anahtar Kelimeler: Film, grafen, dielektrik sabiti, dielektrik kayıp

\section{Investigation of Dielectric Properties of Graphene Filled Starch Films in Wide Frequency Range}

ABSTRACT: In this study, the change of some dielectric properties such as dielectric constant, dielectric loss and loss tangent of films prepared by casting method by adding graphene $(\mathrm{G})$ in different proportions (\% wt 0.5 , $1,2)$ to potato starch (PS) films plasticized with glycerol were investigated. Dielectric constant $(\dot{\varepsilon})$, dielectric loss $\left(\varepsilon^{\prime \prime}\right)$ and loss tangent $(\tan \delta)$ values of pure PS and its composites prepared with G (PSG0.5, PSG1 and PSG2) were determined by impedance analyzer as a function of frequency (between $100 \mathrm{~Hz}$ and $10 \mathrm{kHz}$ ) at room temperature. The dielectric constant, dielectric loss factor and loss tangent values of the starch were found to be 9.20, 4.45 ve 0.48 at $1 \mathrm{kHz}$ constant frequency and at room temperature. In addition, the effect of different proportions of $\mathrm{G}(0.5 \%, 1 \%$ and $2 \%$ by weight $)$ on the dielectric properties of films were investigated. $(0.5 \%, 1 \%$ and $2 \%$ by weight) of the starch on the dielectric properties was investigated. It was observed that as the $\mathrm{G}$ concentration increased, the dielectric constant, dielectric loss and loss tangent values significantly increased compared to the pure starch.

Keywords: Film, graphene, dielectric constant, dielectric loss

\footnotetext{
${ }^{1}$ Gülben TORĞUT (Orcid ID: 0000-0003-1730-1152), Munzur Üniversitesi, Tunceli Meslek Yüksekokulu, Kimya ve Kimyasal İşleme Teknolojileri Bölümü, Tunceli, Türkiye

${ }^{2}$ Nedim GÜRLER (Orcid ID: 0000-0001-5637-8262), Munzur Üniversitesi, Tunceli Meslek Yüksekokulu, Gıda İşleme Bölümü, Tunceli, Türkiye

*Sorumlu Yazar/Corresponding Author: Nedim GÜRLER, e-mail: drnedimgurler@gmail.com; nedimgurler@munzur.edu.tr
} 


\section{GİRiş}

Dielektrik ölçümler, polimerler gibi katı malzemelerin karakterizasyonunda kullanılan ve birçok kimyasal analiz tekniğinden daha kolay gerçekleştirilen en popüler yöntemlerden biridir (Delipınar, 2013; Lökçü, 2013; Torğut ve Demirelli, 2016). Empedans spektroskopisi, elektrolit malzemelerin elektriksel özelliklerinin çoğunu ve bunların elektronik olarak iletken elektrotlarla arayüzlerini karakterize etmek için nispeten yeni ve güçlü bir yöntemdir. Bir malzemenin geçirgenliği, elektromanyetik enerjiyi emme, iletme ve yansıtma yeteneğini ifade eder. Geçirgenlik, dielektrik sabiti $(\dot{\varepsilon})$ ve dielektrik kayıp faktöründen $\left(\varepsilon^{\prime \prime}\right)$ oluşan karmaşık bir niceliktir; burada $\dot{\varepsilon}$, gerçek bileşendir ve maddenin kapasitansı ve elektrik enerjisini depolama yeteneği ile ilgilidir, $\varepsilon^{\prime \prime}$ ise hayali bileşendir ve enerji dağılımının çeşitli soğurma mekanizmaları ile ilgilidir (Everard ve ark., 2006; Koran ve ark., 2014). Kayıp tanjantı, kompleks dielektrik sabitinin sanal kısmının, gerçel kısmına oranıdır. Dielektrikte 1sı olarak açığa çıkan enerji miktarının büyüklüğünü değerlendirmekte kullanılır (İyibakanlar, 2003).

Dielektrikler, esasen bir dış elektrik alan etkisi altında hareket edebilen serbest taşıyıcı bulundurmadıklarından dolayı yalıtkandırlar. Dielektrik malzemeler, bir dış elektrik alana maruz kalması durumda yük veya enerji depolayabilme yeteneği gösterirler (Symth, 1955; Koran, 2018). Elektrik yükleri arasına bir dielektrik malzeme yerleştirildiğinde, sanki birbirlerinden uzaklaştırılmışlar gibi, aralarına etki eden kuvveti azaltır. Bir malzemenin dielektrik sabiti, elektromanyetik sinyallerin malzeme içinde nasıl hareket edeceğini etkilemektedir (Figueiro ve ark., 2006). Dolayısıyla, dielektrik sabiti ve dağılım faktörü, polimerin fiziksel veya kimyasal durumu hakkında daha fazla bilgi sağlar. Polimerin dielektrik işlemi, polar gruplarının termal hareketi ve yük dağılımı ile tanımlanır (Biryan ve ark., 2017).

Genel olarak, polimerik malzemeler düşük dielektrik geçirgenliğe sahiptir. Ancak az miktarda (hacimce \% 1), iletken dolgu maddesi eklenmesi dielektrik geçirgenliği önemli ölçüde artırır (Ahmad ve ark., 2019; Torğut, 2019). Bu bağlamda, karbon siyahı, karbon nanotüpler, grafen, grafen oksit, grafit, gibi dolgular kullanılarak nano boyutta polimerik kompozitler hazırlanmıştır (Torğut ve ark., 2019). Bu nanofiller maddelerin yalıtkan polimer matrisindeki yüksek dağılımı, kompozitlerin gelişmiş dielektrik özelliklerine yol açan daha yüksek arayüz polarizasyonuna da katkıda bulunur (Li ve ark., 2019). Böylece polimerlerin hem mekanik hem de fiziksel özellikleri gelişir. Elastikiyet, hafiflik, işlenebilirlik, termal stabilite $\mathrm{vb}$. gibi benzersiz elektriksel ve mekanik özellikleri birleştiğinde kompozitler geniş uygulama alanları bulmuşlardır (Calame J.P, 2006; Panwar ve ark., 2010). İletken ile doldurulmuş polimer nanokompozitler havacılık ve denizcilik sistemleri, termistörler, enerji depolama cihazlar, kapasitörler, ışık yayan diyotlar, gaz sensörleri, piller, vb. birçok alanda kullanımları ile dünya çapında dikkat çekici hale geldi. Son zamanlarda grafen katkılı nanokompozitler, yüksek dielektrik sabiti ve düşük dielektrik kaybı nedeniyle nano dinamik uygulamaları için bilim insanlarının ilgi odağı olmuştur (Li ve ark., 2011; Zhang ve ark., 2013). Çalışmalarda, polimerik malzemeye iyi dağılmış grafen, polimerin dielektrik sabitinde önemli gelişmeler göstermektedir.

Grafen, $\mathrm{sp}^{21}$ ye bağlı karbon atomlarının iki boyutlu (2D) tek katmanlı altıgen kafes yapısından oluşur (Wang ve ark., 2011; Zheng ve ark., 2013). Son yıllarda grafen, son derece yüksek özgül yüzey alanına, çok yüksek erime noktasına, yüksek taşıyıcı hareketliliğine, mükemmel mekanik özelliklere, kimyasal stabiliteye, yüksek termal / elektrik iletkenliğine ve iyi biyouyumluluk özelliklerine sahip olduğundan dolayı nanokarbon bir malzeme olarak büyük ilgi görmektedir (Kim ve ark., 2010; Liu ve ark., 2013; Yarahmadi ve ark., 2018; Chen ve ark., 2019; Wu ve ark., 2019). Bu üstün özellikler, grafenin biyosensörler, ilaç dağıtım sistemi, süper kapasitörler, polimer nanokompozitler ve kaplamalar gibi çeşitli uygulamalarda kullanılabileceğini ortaya koydu (Xie ve ark., 2014; Sari ve ark., 2017, Karimi ve 
ark., 2017). Son y1llarda, polimerin ana faz ve grafenin ilave faz olduğu polimer nanokompozitler üzerine yapılan çalışmalar büyük ilgi görmektedir. Polimerlerin özelliklerini (özellikle iletkenlik ve mekanik) geliştirdiği için en iyi nanofiller olarak düşünülebilir (Zare ve Rhee, 2017).

Polimer nanokompozitler, fiziksel, mekanik ve biyolojik özelliklerine bağlı olarak mekanik, elektronik ve biyoloji gibi tüm bilim alanlarına sürekli olarak katkıda bulunmaktadır. Son zamanlarda araştırmacılar, çevreye zarar vermeyen doğaları için biyolojik olarak uyumlu ve biyolojik olarak parçalanabilen polimerleri sentezlemenin yanı sıra işlemeye odaklandılar (Usman ve ark. 2016). Şu anda biyopolimerler ile yapılan çalışmalar oldukça ilgi çekmiştir. Biyopolimerler arasında nişasta oldukça düşük maliyeti, doğada bol bulunabilirliği ve biyobozunabilen bir polimer olduğu için dikkat çekmektedir. Ancak, nişasta düşük mekanik mukavemete ve yüksek nem hassasiyetine sahiptir (ÁvilaOrta ve ark. 2018).

$\mathrm{Bu}$ araştırmanın amacı, zayıf elektriksel iletkenlik gösteren patates nişastasına farklı oranlarda grafen ilave ederek hazırlanan filmlerin dielektrik sabiti, dielektrik kayıp faktörü ve kayıp tanjantı değerlerini incelemek ve grafenin bu özellikler üzerindeki etkisini inceleyip birbirleriyle karşılaştırmaktır.

\section{MATERYAL VE METOT}

Çalışmada kullanılan polimer ve filmler yazarların daha önceki çalışmasında sentezlenmiş ve karakterize edilmiştir (Gürler ve Torğut, 2020). Dielektrik sabiti, dielektrik kayıp ve dielektrik kayıp tanjantı gibi malzemenin dielektrik özelliklerini oda sıcaklığında değişen frekanslarda ölçmek için numuneler $15 \mathrm{~mm}$ çapında kesilen ve kalınlığı ölçülen numuneler iki elektrot arasına sabitlenir ve paralel plakalı kondansatör elde edildi. Dielektrik parametrelerin ölçümlerinde bir Novocontrol Technologies (Alpha-AN) empedans analizörü kullanıldı. PN ve PNG kompozit filmlerinin ölçümleri, oda sıcaklığında $100 \mathrm{~Hz}$ ve $10 \mathrm{kHz}$ frekans arasında alındı. Dielektrik parametreler aşağıdaki formüller yardımıyla hesaplandi.

$$
\begin{aligned}
& \varepsilon^{\prime}=\mathrm{C}_{\mathrm{p}} \frac{\mathrm{d}}{\mathrm{A} \varepsilon_{0}} \\
& \varepsilon^{\prime \prime}=\dot{\varepsilon} \times \mathrm{DF} \\
& \tan \delta=\mathrm{DF}=\frac{\varepsilon^{\prime \prime}}{\dot{\varepsilon}}
\end{aligned}
$$

Denklemlerde, $\varepsilon_{0}$, boşluğun dielektrik sabiti olup değeri $8.85 \times 10^{-12} \mathrm{Fm}^{-1}$ dir. $\mathrm{C}$, numunenin kapasitans1 (F), d numunenin çapı $(\mathrm{m})$, A numunenin alanı $\left(\mathrm{m}^{2}\right)$, DF, kayıp faktörüdür.

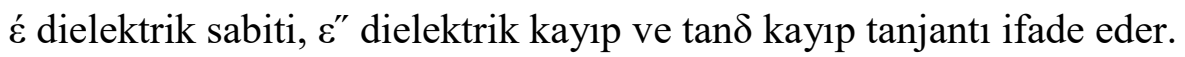

\section{BULGULAR VE TARTIŞMA}

Polimerik malzemeler ve kompozitlerin karakterizasyonunda ve kullanım alanlarını genişletmede dielektrik özelliklerini bilmek önem arzetmektedir. Dielektrik özelliğe sahip malzemeler optik lenslerden uçak sanayisine, cep telefonlarından süper kapasitörlere ve mikrodalga parçacıklarına kadar birçok alanda kullanılmaktadır. Bu çalışmada, gliserol ile plastikleştirilmiş patates nişastası ve kütlece $\% 0.5,1$ ve 2 oranlarında grafen ile hazırlanmış nanokompozitlerin dielektrik sabiti, dielektrik kayıp ve kayıp tanjantı gibi dielektrik özelliklerinin frekansla değişimleri incelenmiştir ve birbirleriyle karşılaştırılmıştır. 
Polimerler alternatif bir elektrik alanında bırakıldığında elektron ve atomlar yer değiştirir, elektrik yük merkezleri kayar ve elektriksel polarizasyon oluşur. Materyale, dişardan bir elektrik alan uygulandığı zaman enerji depolama yeteneğine sahipse "dielektrik" olarak sınıflandırılır. Dielektrik sabiti bir alanın etkisi altında dış elektrik bölgede ne kadar enerji saklandığını ve malzeme içerisinde ne kadar enerji kaybolduğunu gösterir (İyibakanlar ve Oktay, 2007).

Frekanstaki değişimler, malzemenin dielektrik özelliklerini etkileyen en önemli faktördür. Bu nedenle, bu çalışmada grafenin patates nişastasının dielektrik özellikleri üzerine etkisi $100 \mathrm{~Hz}-10 \mathrm{kHz}$ frekans aralığında araştırılmıştır. Ağırlıkça \%0.5, \%1 ve \%2 oranında G katkılı PN kompozitlerinin ve PN'nin oda sıcaklığındaki özelliklerini karşılaştırmak için dielektrik sabiti, dielektrik kayıp ve kayıp tanjantı ölçümleri alınmıştır. Bu değerlerin grafikleri karşılaştırmalı olarak Şekil 1, 2, 3'de çizilmiş ve değerleri Çizelge 1'de özetlenmiştir.

Şekil 1'de nişastanın ve kompozitlerinin dielektrik sabitinin oda sıcaklığında frekansla değişimi görülmektedir. Özellikle düşük frekanslarda $\dot{\varepsilon}$ değerleri, elektronik, atomik, iyonik ve arayüz polarizasyonlarından dolayı daha yüksekken frekans arttıkça azalmaktadır. Ayrıca, tüm numuneler için ara yüzdeki yük taşıyıcı yoğunluğundaki azalmaya bağlı olarak yüksek frekanslarda küçük değişiklik göstererek nerdeyse sabit kalmıştır (Torğut ve ark., 2019; Pihtili ve ark., 2020). Ek olarak elektrik alanda oluşan çift kutupların gevşeme süresi denen denge durumuna ulaşması için zamana ihtiyacı vardır. Yüksek frekanslarda $\varepsilon$ düşüşünün nedenlerinden biri de gevşemek için yeterli zamana sahip olmamasıdır. Yüksek frekanslarda sadece elektriksel polarizasyon oluşur, bu nedenle dipollerin sayısı

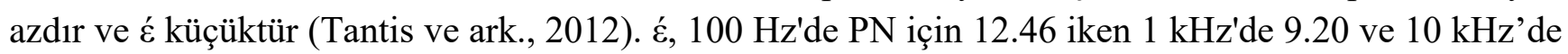
8'dir. Benzer şekilde, PNG0.5 için $\varepsilon$ değeri 100 Hz'de 16 iken 1 kHz'de 10.77 ve 10 kHz'de 9.4'tür. Şekil 1 incelendiğinde, kompozit serisinde grafen oranındaki artışla $\varepsilon$ değerlerinin büyük oranda arttığı açıktır. $\varepsilon$ değeri 1 kHz'de ağırlıkça \% 1 ve \%2 grafen içeren kompozitler için sırasıyla 11.97 ve 17.96 olarak ölçülmüştür. Sonuçlar Şekil 1'de özetlenmiştir. $\varepsilon$ değerindeki artışın nedeni, grafen oranıyla birlikte yük taşıyıcıların kolayca geçebildiği elektrik alanındaki artıştan kaynaklı olabilir (Paszkiewicz ve ark., 2017). Aynı zamanda $\varepsilon$ değerindeki bu iyileşme, kompozitlerde grafen varlığına bağlı olarak artan dipollerin oryantasyonu ve arayüzey polarizasyonuna bağlanmaktadır (Goyal ve ark. 2009; Lai ve ark., 2014).

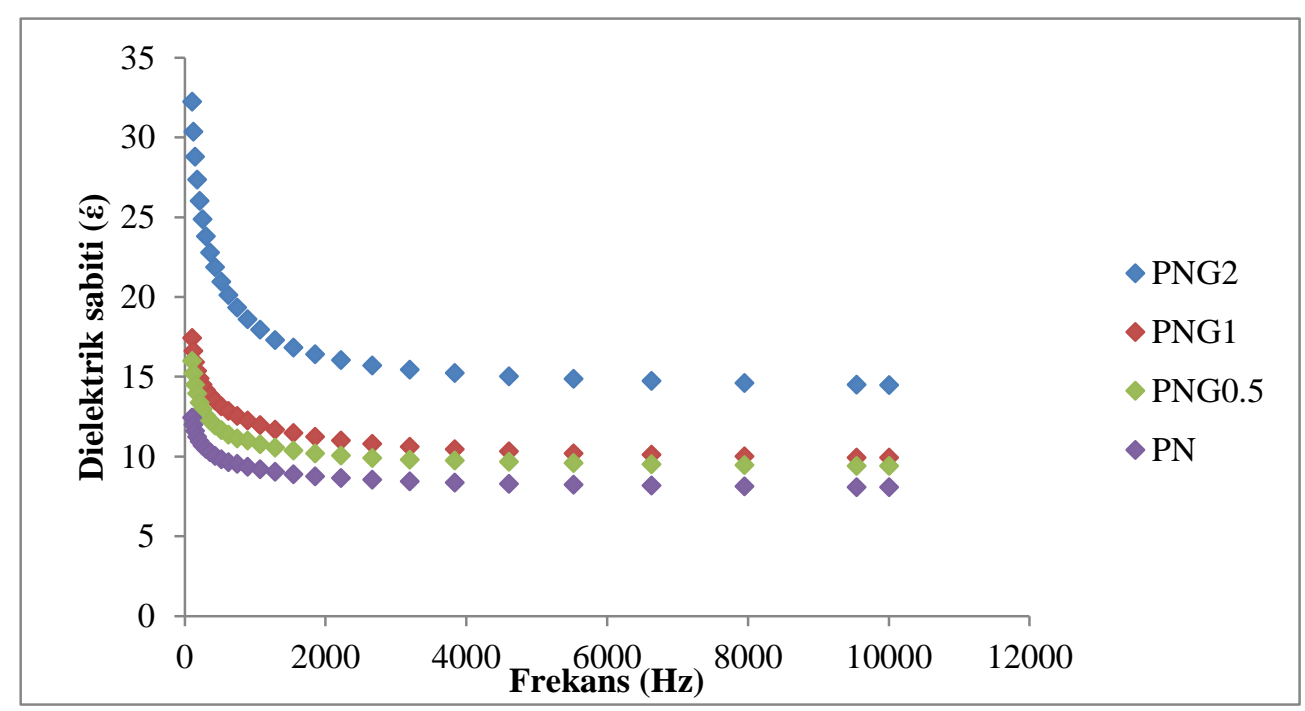

Şekil 1. PN ve G katkılı kompozitlerinin dielektrik sabitinin frekansla değişimi 
Çizelge 1. PN ve G katkılı kompozitlerinin dielektrik sonuçları

\begin{tabular}{ccccccc}
\hline $\begin{array}{c}\text { Katkı yüzdesi } \\
\mathbf{\%} \mathbf{G}\end{array}$ & $\begin{array}{c}\text { Dielektrik sabiti } \\
(\boldsymbol{\varepsilon}) \mathbf{1 0 0 H z}\end{array}$ & $\begin{array}{c}\text { Dielektrik sabiti }(\boldsymbol{\varepsilon}) \\
\mathbf{1} \mathbf{~ k H z}\end{array}$ & $\begin{array}{c}\text { Dielektrik kayıp } \\
\left(\boldsymbol{\varepsilon}^{\prime \prime}\right) \mathbf{1 0 0 ~ H z}\end{array}$ & $\begin{array}{c}\text { Dielektrik kayıp } \\
\left(\boldsymbol{\varepsilon}^{\prime \prime}\right) \mathbf{1} \mathbf{~ k H z}\end{array}$ & $\begin{array}{c}\text { Kayıp tanjantı } \\
(\tan \boldsymbol{)}) \mathbf{1 0 0} \mathbf{H z}\end{array}$ & $\begin{array}{c}\text { Kayıp tanjantı } \\
(\mathbf{t a n} \boldsymbol{)}) \mathbf{1} \mathbf{~ k H z}\end{array}$ \\
\hline 0 & 12.46 & 9.20 & 33.93 & 4.45 & 1.69 & 0.48 \\
0.5 & 16.00 & 10.77 & 48.85 & 6.71 & 2.72 & 0.53 \\
1 & 17.43 & 11.97 & 52.49 & 6.81 & 2.80 & 0.57 \\
2 & 32.23 & 17.96 & 54.76 & 9.5 & 3.28 & 0.62 \\
\hline
\end{tabular}

Malzeme seçiminde önemli bir parametre olan dielektrik kayıp $\left(\varepsilon^{\prime \prime}\right)$ malzemeye verilen enerjinin malzeme içinde ne kadarının 1sı olarak tüketildiğini veren bir parametredir (Canbulat, 2019). Şekil 2'de PN ve grafenle hazırlanmış kompozitleri için, oda sıcaklığında frekansın bir fonksiyonu olarak çizilen dielektrik kayıp grafiği görülmektedir. Bütün numuneler için $\varepsilon^{\prime \prime}$ değerlerinin artan frekansla azaldığı net bir şekilde görülmektedir. Yüksek frekanslardaki düşük $\varepsilon^{\prime \prime}$ değeri, polimerde arayüzeyden kaynaklanan gevşeme olaylarına bağlanabilir (Pandey ve ark., 2010). Aynı zamanda düşük frekansta yüksek $\varepsilon^{\prime \prime}$ değeri, malzemeler içindeki serbest yük hareketinden kaynaklanmaktadır (Srivastava ve Mehra, 2008). ع", 100 Hz'de PN için 33.93 iken 1 kHz'de 4.45 ve $10 \mathrm{kHz}$ 'de 1.05'dir (Çizelge 1). Dolgu maddesinin miktarındaki artış kompozit polariteyi artırdığından $\varepsilon^{\prime \prime}$ 'yi de artırmıştır (George ve ark., 1999; Nair ve ark., 2013). $1 \mathrm{kHz}$ frekansta PN için 4.45 olan $\varepsilon^{\prime \prime}$, PNG0.5, PNG1 ve PNG2 için sirasıly 6.71, 6.81 ve 9.5 olarak ölçülmüştür.

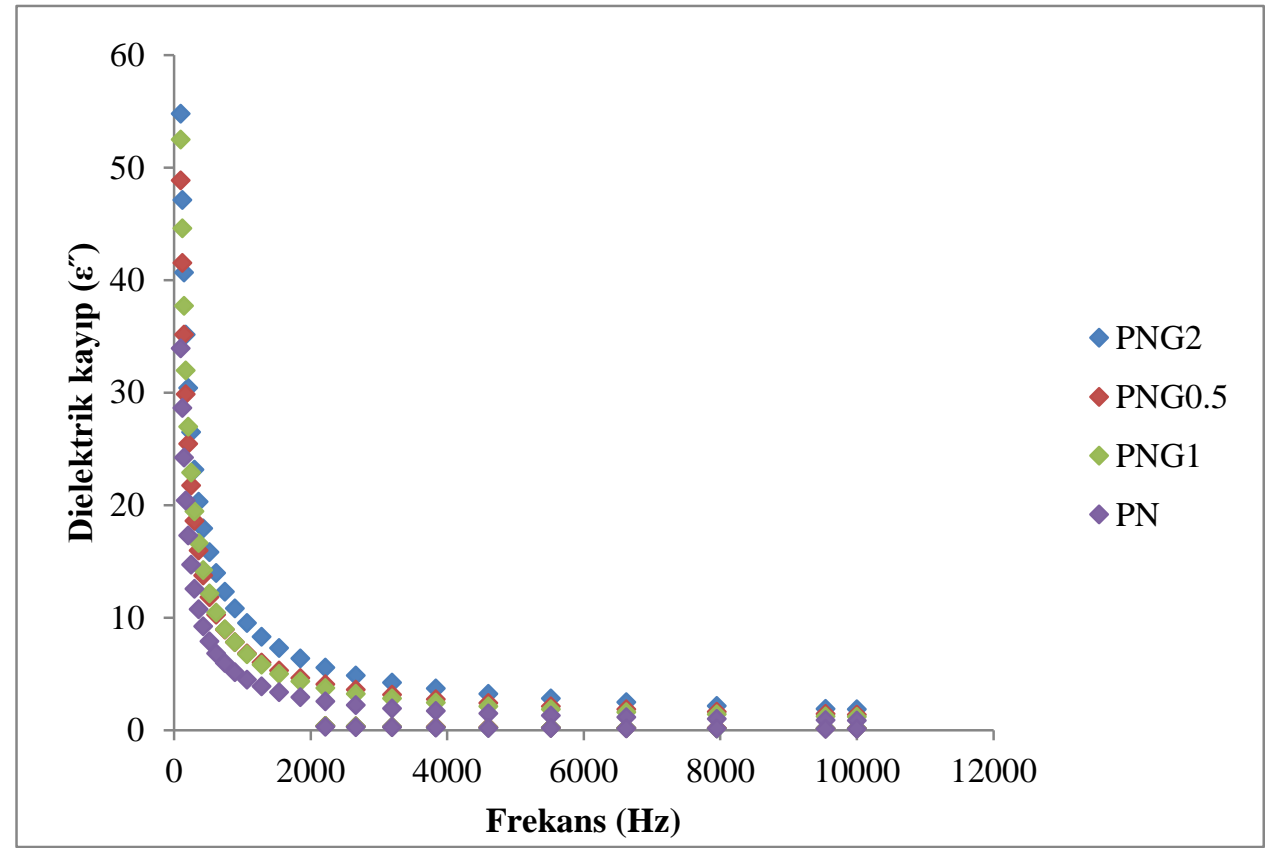

Şekil 2. PN ve G katkılı kompozitlerinin dielektrik kaybının frekansla değişimi

Dielektrik kayıp faktörü veya kayıp tanjantı ise dielektrik kayıplardan dolayı elektromanyetik enerjinin 1sı enerjisine dönüştüğünün ölçüsünü ifade eder (Canbulat, 2019). Nişasta ve grafen katkılı kompozitleri için tan $\delta$ 'ın frekansa göre değişimi Şekil 3 'te verilmiştir. Grafiklerden de görüldüğü gibi, frekans arttıkça bütün numuneler için tan $\delta$ azalmaktadır. Bu sonuç birçok çalışma ile uyum içerisindedir (İyibakanlar, 2003; Karasu ve ark., 2016). G katkısı tan $\delta$ değerlerinde artışa neden olmuştur. Sonuçlar Çizelge 1'de özetlenmiştir. 


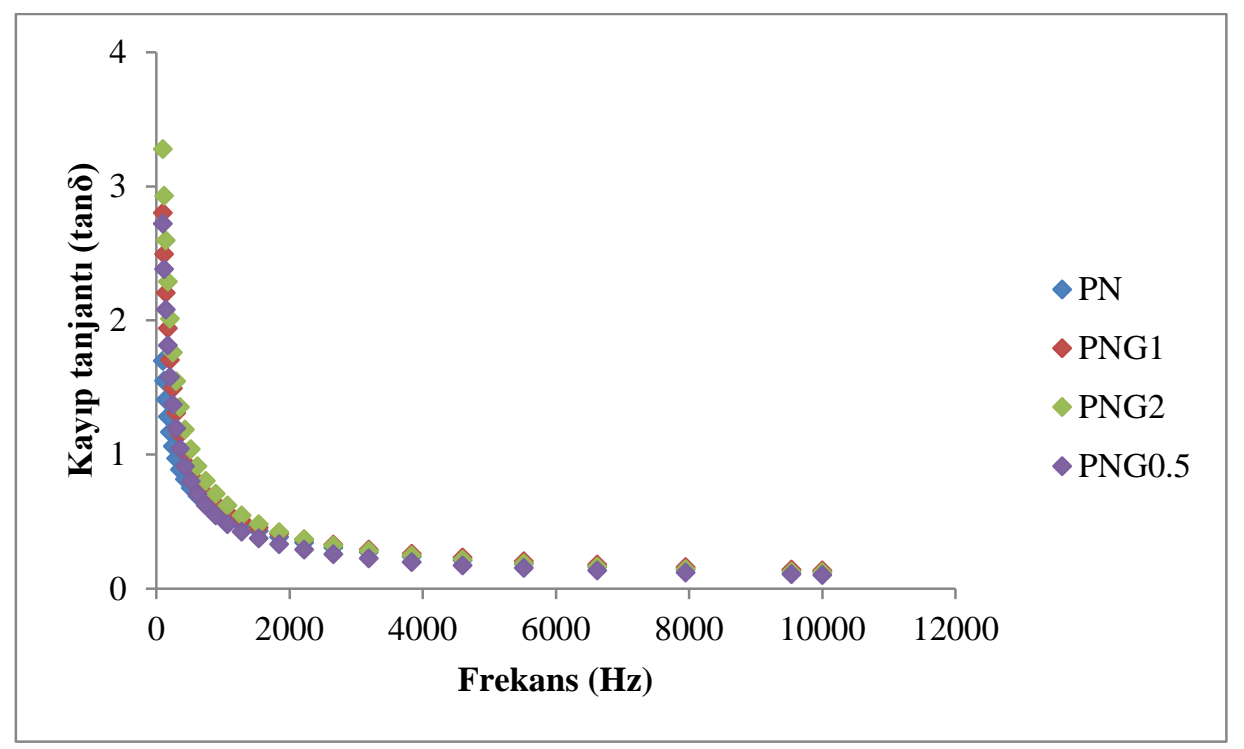

Şekil 3. PN ve G katkılı kompozitlerinin kayıp tanjantının frekansla değişimi

Şekil 4, Şekil 5 ve Şekil 6'da $100 \mathrm{~Hz}$ sabit frekansta sırasıyla dielektrik sabiti, dielektrik kayıp ve kayıp tanjantın grafenin yüzde miktarıyla değişim eğrileri görülmektedir. Her üç şekilde de grafenin patates nişastasının dielektrik özellikleri üzerine büyük etkisinin olduğu açıktır.

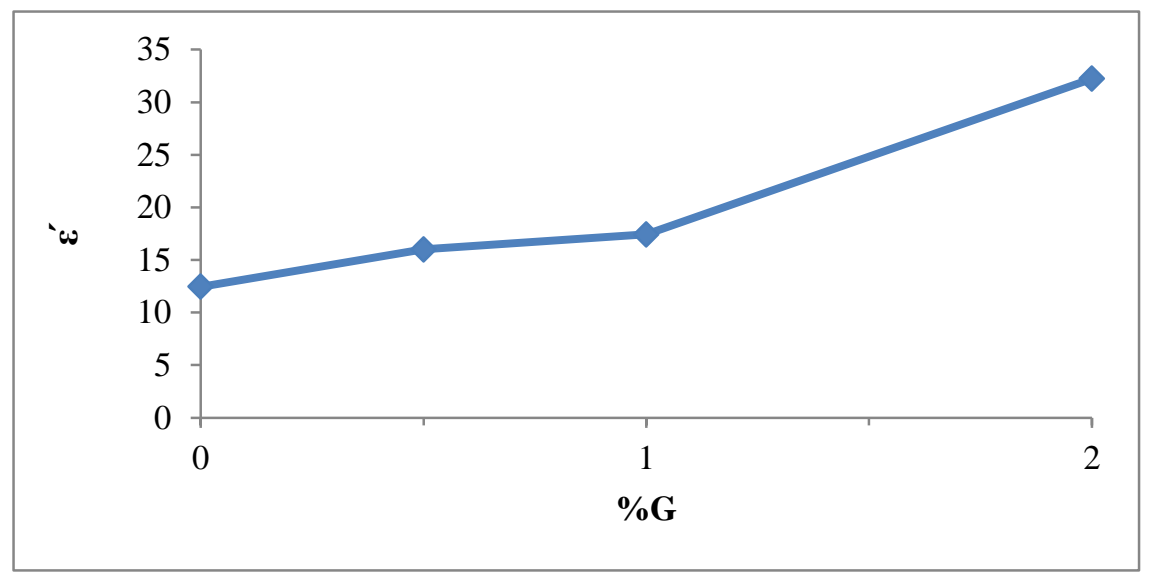

Şekil 4. $100 \mathrm{~Hz}$ frekansta É’nin \% G ile değişimi

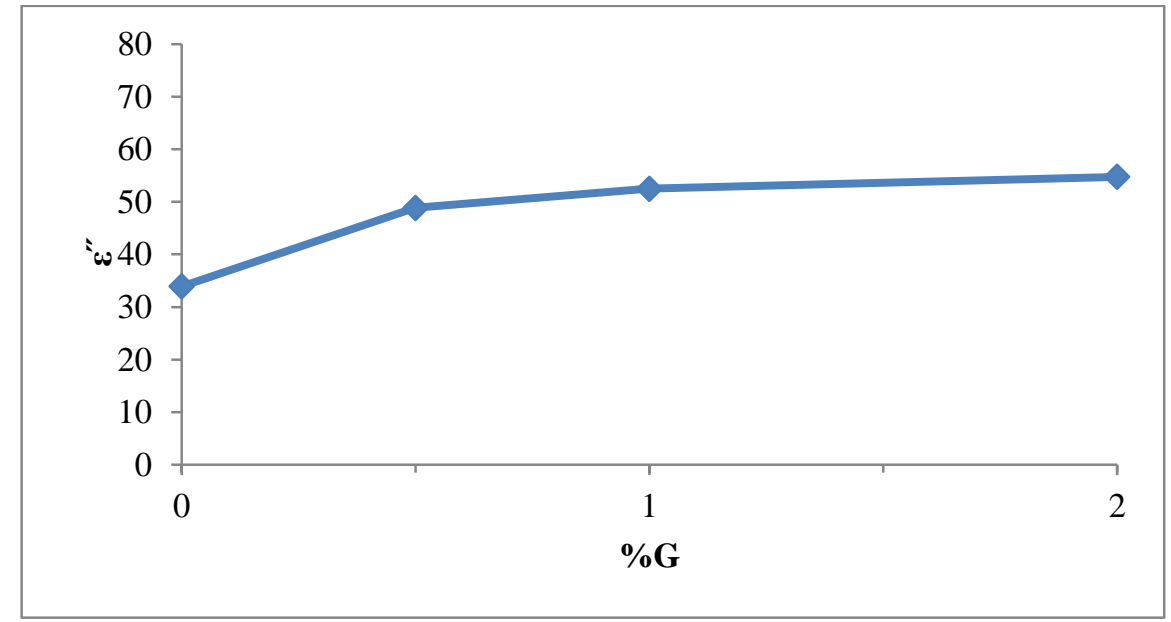

Şekil 5. $100 \mathrm{~Hz}$ frekansta $\varepsilon^{\prime \prime \prime} 1 \mathrm{n} \% \mathrm{G}$ ile değişimi 


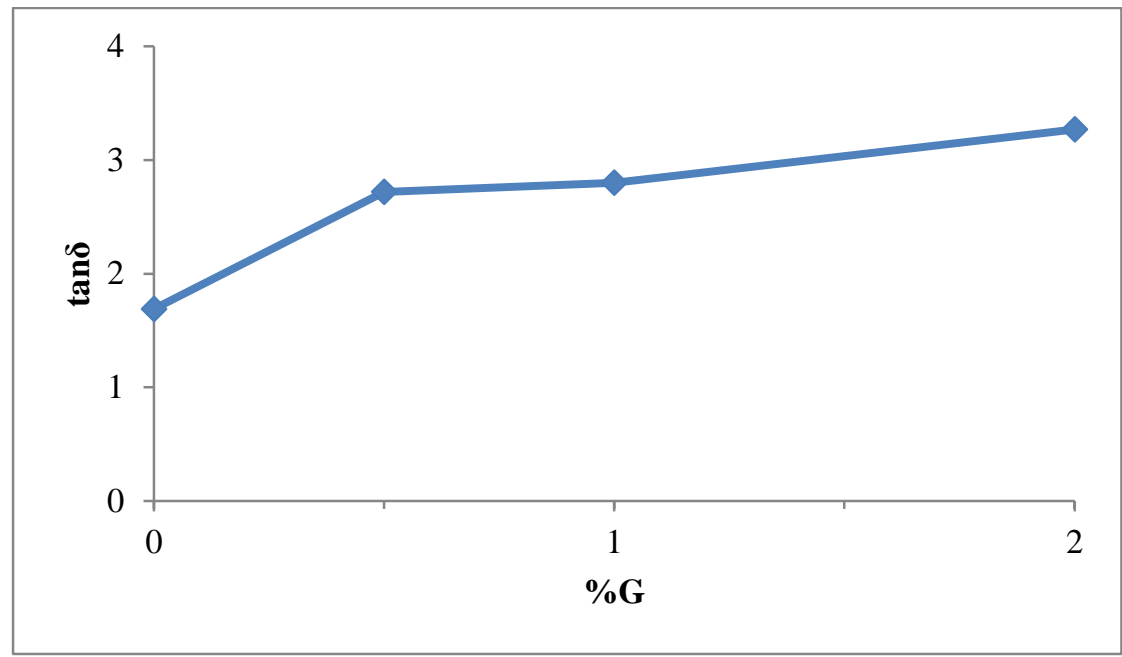

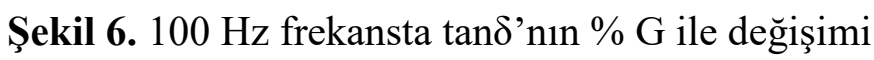

Tüm bu sonuçlar incelendiğinde bileşiklerin dielektrik özelliklerinin frekansa karşı duyarlı olduğu ve frekansın artması ile azaldığı görülmüştür. $\mathrm{Bu}$ tür malzemeler elektriksel yalıtkan, dielektrik kapasitörü ya da mikrodalga aygıtlarının parçalarında kullanılabilme gibi teknolojik uygulamaları nedeniyle büyük ilgi görmektedir (Yuxing ve David, 2008).

\section{SONUC}

Bu çalışmada gliserol ile plastikleştirilmiş patates nişastası ve bunun kütlece farklı yüzdelerde grafen ile hazırlanmış kompozitlerinin dielektrik özellikleri empedans spektroskopisi teknikleri kullanılarak $100 \mathrm{~Hz}-10 \mathrm{kHz}$ frekans aralığında incelenmiştir. Kompozit yapılarda bulunan grafen katkı maddesi maddenin içerisinde arayüzey kutuplanmasına neden olacak yükler bulundurduğundan düşük frekanslarda dielektrik sabiti ve dielektrik kayıp oldukça büyük değerler almıştır. Frekans arttıkça kutuplu moleküllerin sayısı da arttığından $\varepsilon$ ve $\varepsilon^{\prime \prime}$ azalmış ve yeterince molekül kutuplandıktan sonra frekansla değişimi oldukça azalarak nerdeyse sabit kalmıştır. Az miktarda grafen katkısının nişastanın dielektrik sabitleri üzerinde önemli etkisi olduğu görülmektedir. Aynı şekilde nişasta ve kompozitlerinin kayıp tanjantı düşük frekanslarda büyük iken artan frekansla azalmıştır. Grafen nişasta filmlerinin dielektrik özellikleri üzerinde önemli bir gelişme sağladığından bu filmlere yeni özellikler kazandırmış ve kullanım alanlarını artırmıştır. Bu tür maddeler, dielektrik kapasitörü, cep telefonları, uydu haberleşme sistemleri, askeri arama radarları ve mikrodalga aygıtlarının parçalarına kadar çok geniş bir uygulama alanına sahiptirler.

\section{Çıkar Çatışması}

Makale yazarları aralarında herhangi bir çıkar çatışması olmadığını beyan ederler.

\section{Yazar Katkısı}

Yazarlar makaleye eşit oranda katkı sağlamış olduklarını beyan eder.

\section{KAYNAKLAR}

Ahmad MW, Dey B, Sarkhel G, Bag DS, Choudhury A, 2019. Exfoliated Graphene Reinforced Polybenzimidazole Nanocomposites With High Dielectric Permittivity At Low Percolation Threshold. Journal of Molecular Structure, 1177: 491-498.

Ávila-Orta CA, Soriano Corral F, Fonseca-Florido HA, Estrada Aguilar FI, Solís Rosales SG, Mata Padilla JM, Morones PG, Tavizon SF, Hernández-Hernández E, 2018. Starch-Graphene Oxide Bionanocomposites Prepared Through Melt Mixing. Journal of Applied Polymer Science, 135(12): 46037. 
Biryan F, Demirelli K, Torğut G, Pihtılı G, 2017. Synthesis, Thermal Degradation And Dielectric Properties of Poly [2-Hydroxy, 3-(1-Naphthyloxy) Propyl Methacrylate]. Polymer Bulletin, 74(2): 583-602.

Calame JP, 2006. Finite Difference Simulations of Permittivity And Electric Field Statistics in Ceramic-Polymer Composites for Capacitor Applications. Journal of Applied Physics, 99(8): 084101.

Canbulat N, (2019). Pres Kalıplama Pestilinin Mekanik ve Elektrik Özelliklerinin İncelenmesi, Yüksek Lisans Tezi, Balıkesir Üniversitesi Fen Bilimleri Enstitüsü, 2019.

Chen J, Long Z, Wang S, Meng Y, Zhang G, Nie S, 2019. Biodegradable Blends of Graphene Quantum Dots and Thermoplastic Starch with Solid-State Photoluminescent and Conductive Properties. International Journal of Biological Macromolecules, 139: 367-376.

Delipınar Didem, 2013. Probertit, Elektrokoagülasyon Termal Atık Ve Elektrokoagülasyon Bor Atığın Dielektrik Özelliklerinin Empedans Spektroskopisi Yöntemi İle İncelenmesi. Yıldız Teknik Üniversitesi, Fen Bilimleri Enstitüsü, Yüksek Lisans Tezi, Fizik Anabilim Dalı, İstanbul

Everard CD, Fagan CC, O'donnell CP, O'callaghan DJ, Lyng JG, 2006. Dielectric Properties of Process Cheese from 0.3 to $3 \mathrm{GHz}$. Journal of Food Engineering, 75(3): 415-422.

Figueiro SD, Macedo AA. M, Melo MRS, Freitas ALP, Moreira RA, De Oliveira RS, Goes JC, Sombra ASB, 2006. On The Dielectric Behaviour of Collagen-Algal Sulfated Polysaccharide Blends: Effect of Glutaraldehyde Crosslinking. Biophysical Chemistry, 120(2): 154-159.

George S, Varughese KT, Thomas S, 1999. Dielectric Properties of İsotactic Polypropylene/Nitrile Rubber Blends: Effects of Blend Ratio, Filler Addition, and Dynamic Vulcanization. Journal of Applied Polymer Science, 73(2): 255-270.

Goyal RK, Jagadale PA, Mulik UP, 2009. Thermal, Mechanical, and Dielectric Properties Of Polystyrene/Expanded Graphite Nanocomposites. Journal of Applied Polymer Science, 111(4): 2071-2077.

Gürler N, Torğut G, 2020. Graphene-Reinforced Potato Starch Composite Films: Improvement of Mechanical, Barrier and Electrical Properties. Polymer Composites.

İyibakanlar, G, 2003. Polimerlerin Dielektrik Özelliklerinin Sıcaklık ve Frekansla Değişimlerinin İncelenmesi. Doktora Tezi, Fen Bilimleri Enstitüsü Sivil Havacılık Anabilim Dalı, Eskişehir.

İyibakanlar G, Oktay A, 2007. Bazı Polimerlerin Dielektrik Özelliklerinin Frekansla Değişimlerinin İncelenmesi. Journal of Aeronautics \& Space Technologies/Havacilik ve Uzay Teknolojileri Dergisi, 3(1).

Karasu S, Öztürk A, Şağban HM, Özmen ÖT, 2016. Au/P3HT:PCBM/n-Si Schottky Bariyer Diyotlarda PCBM Konsantrasyonunun Kapasitans-Voltaj (C-V) ve İletkenlik-Voltaj (G/w-V) Karakteristiklerine Etkisi ve Dielektrik Özelliklerin İncelemesi, Düzce Üniversitesi Bilim ve Teknoloji Dergisi, 4.

Karimi B, Ramezanzadeh B, 2017. A Comparative Study on The Effects of Ultrathin Luminescent Graphene Oxide Quantum Dot (GOQD) and Graphene Oxide (GO) Nanosheets on The İnterfacial İnteractions and Mechanical Properties of an Epoxy Composite. Journal of Colloid And Interface Science, 493, 62-76.

Kim H, Abdala AA, Macosko CW, 2010. Graphene/Polymer Nanocomposites. Macromolecules, 43(16): 65156530.

Koran K, Özen F, Torğut G, Pihtılı G, Çil E, Görgülü AO, Arslan M, 2014. Synthesis, Characterization and Dielectric Properties of Phosphazenes Containing Chalcones. Polyhedron, 79: 213-220.

Koran K, 2018. 2,2-(3-(Sübstitüe-florofenil)-1-(4-oksifenil)prop-2-en-1-one)-4,4,6,6- bis[spiro(2',2"-dioksi1',1"-bifenilil]SiklotrifosfazenlerinDielektrik ve Termal Özellikleri. Afyon Kocatepe Üniversitesi Fen ve Mühendislik Bilimleri Dergisi, 18: 458-467.

Lai M, Yu S, Sun R, 2014. Ceramic/Polymer Composites with Enhanced Permittivity and Low Dielectric Loss Through Grafting Modification of Polymer Matrix By Polyethylene Glycol. Materials Letters, 122: 45-48.

Li B, Zhong WH, 2011. Review on Polymer/Graphite Nanoplatelet Nanocomposites. Journal of Materials Science, 46(17): 5595-5614.

Li W, Song Z, Qian J, Tan Z, Chu H, Wu X, Nie W, Ran X, 2019. Enhancing Conjugation Degree and İnterfacial İnteractions to Enhance Dielectric Properties of Noncovalent Functionalized Graphene/Poly (Vinylidene Fluoride) Composites. Carbon, 141: 728-738.

Liu J, Cui L, Losic D, 2013. Graphene and Graphene Oxide as New Nanocarriers for Drug Delivery Applications. Acta Biomaterialia, 9(12): 9243-9257.

Lökçü, E, 2013. Spinel Mikrodalga Dielektrik Seramiklerinin Polimerik Jel Yöntemi İle Üretimi Ve Karakterizasyonu. İstanbul Teknik Üniversitesi, Fen Bilimleri Enstitüsü, Yüksek Lisans Tezi, Metalurji ve Malzeme Mühendisliği Anabilim Dalı, İstanbul.

Nair AB, Kurian P and Joseph R, 2013. European Polymer Journal. 49: 247. 
Pandey K, Dwivedi MM, Singh M, Agrawal SL, 2010. Studies of Dielectric Relaxation and Ac Conductivity in [(100- X) PEO+ Xnh 4 SCN]: Al-Zn Ferrite Nano Composite Polymer Electrolyte. Journal of Polymer Research, 17(1): 127.

Panwar V, Park JO, Park SH, Kumar S, Mehra RM, 2010. Electrical, Dielectric, and Electromagnetic Shielding Properties of Polypropylene-Graphite Composites. Journal of Applied Polymer Science, 115(3): 13061314.

Paszkiewicz S, Szymczyk A, Pilawka R, Przybyszewski B, Czulak A, RosŁaniec Z, 2017. Improved Thermal Conductivity of Poly (trimethylene terephthalate-block-poly (tetramethylene oxide) Based Nanocomposites Containing Hybrid Single-Walled Carbon Nanotubes/Graphene Nanoplatelets Fillers. Advances in Polymer Technology, 36(2): 236-242.

Pihtili G, Torğut G, Biryan F, 2020. Electrical Properties of Two-Armed Poly (E-CL-Co-BMA) Composites Filled with Bentonite. Journal of Polymer Research, 27: 156.

Sari MG, Shamshiri M., Ramezanzadeh B, 2017. Fabricating an Epoxy Composite Coating With Enhanced Corrosion Resistance Through Impregnation of Functionalized Graphene Oxide-Co-Montmorillonite Nanoplatelet. Corrosion Science, 129: 38-53.

Srivastava NK, Mehra RM, 2008. Study of Structural, Electrical, and Dielectric Properties of Polystyrene/Foliated Graphite Nanocomposite Developed via In Situ Polymerization. Journal of Applied Polymer Science, 109(6): 3991-3999.

Symth CP, 1955. Dielectric Behaviour and Structure. McGraw-Hill, New York, 52-61: 202-215.

Tantis I, Psarras G. C, Tasis D, 2012. Functionalized Graphene-Poly (Vinyl Alcohol) Nanocomposites: Physical and Dielectric Properties. Express Polym Lett 6 (4): 283-292.

Torgut G, Demirelli K, 2016. Block Copolymerization of Methylmethacrylate via ATRP Method Using a Macroinitiator Produced By Ring Opening Polymerization: Characterization, Dielectric Properties, and a Kinetic Investigation. Journal of Macromolecular Science, Part A, 53(11): 669-676.

Torğut G, 2019. Fabrication, Characterization of Poly (MA-Co-NIPA)-Graphene Composites and Optimization The Dielectric Properties Using The Response Surface Method (RSM). Polymer Testing, 76: 312-319.

Torğut G, Biryan F, Demirelli K, 2019. Effect of Graphite Particle Fillers on Dielectric and Conductivity Properties of Poly (NIPAM-Co-HEMA). Bulletin of Materials Science, 42(5): 244.

Usman A, Hussain Z, Riaz A, Khan AN, 2016. Enhanced Mechanical, Thermal and Antimicrobial Properties of Poly (Vinyl Alcohol)/Graphene Oxide/Starch/Silver Nanocomposites Films. Carbohydrate Polymers, 153: 592-599.

Wang X, Yang H, Song L, Hu Y, Xing W, Lu H, 2011. Morphology, Mechanical and Thermal Properties of Graphene-Reinforced Poly (Butylene Succinate) Nanocomposites. Composites Science and Technology, 72(1): 1-6.

Wu Z, Huang Y, Xiao L, Lin D, Yang Y, Wang H, Yang H, Wu D, Chen H, Qin W, 2019. Physical Properties and Structural Characterization of Starch/Polyvinyl Alcohol/Graphene Oxide Composite Films. International Journal of Biological Macromolecules, 123: 569-575.

Xie Y, Liu Y, Zhao Y, Tsang YH, Lau SP, Huang H, Chai Y, 2014. Stretchable All-Solid-State Supercapacitor with Wavy Shaped Polyaniline/Graphene Electrode. Journal of Materials Chemistry A, 2(24): 9142-9149.

Yarahmadi E, Didehban K, Sari, MG, Saeb MR, Shabanian M, Aryanasab F, Zarrintaj P, Paran, S MR, Mozafari M, Rallini M, Puglia D, 2018. Development and Curing Potential of Epoxy/Starch-Functionalized Graphene Oxide Nanocomposite Coatings. Progress in Organic Coatings, 119: 194-202.

Yuxing R, David CL, 2008. Properties and Microstructures of Lowtemperature Processable Ultralow-Dielectric Porous Polyimide Films. Journal of Electronic Materials, 37: 21-28.

Zare Y, Rhee KY, 2017. Development of a Model for Electrical Conductivity of Polymer/Graphene Nanocomposites Assuming İterphase and Tunneling Regions in Conductive Networks. Industrial \& Engineering Chemistry Research, 56(32): 9107-9115.

Zhang XJ, Wang GS, Wei YZ, Guo L, Cao MS, 2013. Polymer-Composite with High Dielectric Constant and Enhanced Absorption Properties Based on Graphene-Cus Nanocomposites and Polyvinylidene Fluoride. Journal of Materials Chemistry A, 1(39): 12115-12122.

Zheng P, Ma T, Ma X, 2013. Fabrication and Properties of Starch-Grafted Graphene Nanosheet/Plasticized-Starch Composites. Industrial \& Engineering Chemistry Research, 52(39): 14201-14207. 